\title{
Effects of 5-hydroxy-4'-nitro-7-propionyloxy-genistein on inhibiting proliferation and invasion via activating reactive oxygen species in human ovarian cancer A2780/DDP cells
}

\author{
JUN BAI, BIN-JIAN YANG and XIN LUO \\ Department of Obstetrics and Gynecology, The First Clinical School of Jinan University, \\ Guangzhou, Guangdong 510632, P.R. China
}

Received March 14, 2017; Accepted November 22, 2017

DOI: $10.3892 / \mathrm{ol} .2018 .7938$

\begin{abstract}
. 5-hydroxy-4'-nitro-7-propionyloxy-genistein (HNPG), a novel synthetic isoflavone derivative, was demonstrated to possess antitumor activity in gastric cancer and breast cancer in vitro, but its antitumor effect and mechanism in ovarian cancer has not been characterized. The aim of the present study was to investigate the effects of HNPG on inhibiting the proliferation and invasion in human ovarian cancer A2780 cell lines of cisplatin resistance (A2780/DDP) and elucidate its underlying molecular mechanism. The results indicated that HNPG presented with marked antitumor activity against A2780/DDP cells in vitro, significantly inhibited the rates of proliferation, clone formation, invasion and metastasis, and markedly induced apoptosis in dose- and time-dependent manner. Simultaneously, levels of reactive oxygen species (ROS) were increased and mitochondrial membrane potential was decreased. In addition, Bcl-2 expression was downregulated, Bax expression was upregulated, and the ratio of $\mathrm{Bcl}-2 / \mathrm{Bax}$ was decreased. Concurrently, levels of Cyt-C were markedly enhanced and the caspase cascade was triggered. Taken together, the results suggested that HNPG exerted anticancer effects through promoting ROS accumulation in cells, triggering mitochondrial apoptotic pathways and ultimately resulting in cells apoptosis. Therefore, HNPG serves as a potential candidate in the chemoprevention and/or treatment of cisplatin-resistant human ovarian cancer.
\end{abstract}

\section{Introduction}

Cisplatin (DDP) is widely used in treating ovarian cancer and has demonstrated a marked therapeutic effect in its clinical application. However, during the treatment progress,

Correspondence to: Dr Xin Luo, Department of Obstetrics and Gynecology, The First Clinical School of Jinan University, 601 West Huangpu Avenue, Guangzhou, Guangdong 510632, P.R. China

E-mail: tluox@jnu.edu.cn

Key words: 5-hydroxy-4'-nitro-7-propionyloxy-genistein, proliferation, invasion, apoptosis, reactive oxygen species the generation of DDP resistance has become an obstacle to successful treatment $(1,2)$. It is well-known that when DDP is administered to patients, certain biological phenomena will inevitably occur, such as a gradual reduction in intracellular drug accumulation, inactivation of the general desired effects of the treatment, improvements in the DNA repair ability of cancer cells, alterations of the apoptosis pathway of the tumor cells, and certain regulatory actions of activated indirect signaling pathways, which directly results in the generation of DDP resistance. These may increase the incidence or severity of these events, even causing complete treatment failure (3-5). One strategy to overcome resistance to DDP is to develop novel chemotherapeutic drugs with less or no side effects, which has become an important topic in the field of cancer biology, particularly in ovarian cancer.

Previous studies examining the structure-activity associations of natural isoflavones with antitumor responses have demonstrated that benzene rings with hydroxyls in the seventh or fifth carbon atom in the primary chain (C-7 or C-5), or with three hydroxyls in whole chemical structure, possess higher rates of pharmacological activities $(6,7)$. The hydroxyl of C-5 in isoflavones is the necessary chemical group that retains the antitumor activity (8). Isoflavones in that the hydroxyl of C-4' is superseded by an $\mathrm{NO}_{2}$ group will exhibit increased antitumor bioactivity in comparison to the original isoflavones (9). 5-hydroxy-4'-nitro-7-propionyloxy- genistein (HNPG) is a novel synthetic isoflavone derivative that possesses a nitro group in C-4', a hydroxyl group at C-5 and a propionyloxy group at C-7, and it was observed that HNPG exhibited an inhibition of proliferation in gastric and breast cancer via an MTT assay and a 5-acetylene-2'-deoxypyrimidine nucleoside staining method (10) in vitro, but its antitumor effect has not been examined by other experimental forms, and its molecular biological mechanism has not been investigated $(11,12)$, its role in ovarian cancer also remains uncharacterized.

In the present study, the anticancer effects of HNPG in A2780/DDP cells were evaluated in vitro, and the results demonstrated that HNPG may inhibit proliferation, clone formation, invasion and metastasis and induce apoptosis in A2780/DDP cells, which may attribute to its ability to increase the accumulation of reactive oxygen species (ROS) in cells, decrease the mitochondrial membrane potential $(\Delta \psi \mathrm{m})$, regulate the 
ratio of $\mathrm{B}$-cell lymphoma $2(\mathrm{Bcl}-2) / \mathrm{Bcl}-2$-associated $\mathrm{X}$ protein (Bax) and release Cytochrome C (Cyt-C) from the mitochondria, triggering a caspase cascade and inducing apoptosis, which not only demonstrated more researching patterns of the antitumor effects of HNPG, but also highlighted the basic molecular biological mechanism of HNPG compared with previous reports $(11,12)$.

\section{Materials and methods}

Reagents. HNPG was synthesized in the Department of Obstetrics and Gynecology, The First Clinical School of Jinan University (Guangzhou, China) as described previously (12), with minor modifications; this reagent is a pale yellow crystalline powder with a molecular formula $\mathrm{C}_{18} \mathrm{H}_{13} \mathrm{O}_{7} \mathrm{~N}$ and a molecular weight of 355 , and its chemical structure is presented in Fig 1. HNPG was dissolved in dimethyl sulfoxide (DMSO) into a $1 \mathrm{mM}$ stock solution and stored until use, and the maximal concentration of DMSO did not exceed $0.1 \%(\mathrm{v} / \mathrm{v})$, as this concentration does not exhibit an inhibitory effect on cell proliferation. DMSO, PBS, MTT and Giemsa, crystal violet and hematoxylin \& eosin (H\&E) stains were all obtained from Beyotime Institute of Biotechnology, Co., Ltd. (Shanghai, China). Matrige ${ }^{\mathrm{TM}}$ was purchased from Shanghai Invitrogen Biological Technology Co., Ltd. (Shanghai, China). Specific antibodies for rabbit anti-Bcl-2 (cat. no. A0040-1; dilution, 1:1,000), rabbit anti-Bax (cat. no. A00183; dilution, 1:1,000), rabbit anti-Cyt-C (cat. no. A03529; dilution, 1:1,000), rabbit anti-cleaved caspase-9 (cat. no. BM4521; dilution, 1:1,000), rabbit anti-cleaved caspase-3 (cat. no. BM3937; dilution, 1:1,000), rabbit anti-GAPDH antibodies (cat. no. A00227-1; dilution, 1:1,000) and horseradish peroxidase-conjugated secondary rabbit antibody used for western blotting (cat. no. BA1082; dilution, 1:5,000) were all obtained from Boster Biological Technology Co., Ltd. (Wuhan, China).

Cell culture and grouping. A2780-cisR cell line was purchased from the China Centre for Type Culture Collection (Wuhan, Hubei, China) and cultured at $37^{\circ} \mathrm{C}$ in humidified $5 \% \mathrm{CO}_{2}$ in Dulbecco's modified Eagle's medium (DMEM; Hyclone; GE Healthcare Life Sciences, Logan, UT, USA) supplemented with $10 \%$ fetal bovine serum (FBS; Hangzhou Sijiqing Biological Engineering Materials Co., Ltd., Hangzhou, China), penicillin (100 U/ml, Qilu Pharmaceutical Co., Ltd., Jinan, China) and streptomycin $(100 \mu \mathrm{g} / \mathrm{ml}$, Shandong Pharmaceutical Co., Ltd., Jinan, Shandong, China). The cells were then divided in four groups: The control group (0.1\% DMSO) and the different concentrations of HNPG (5, 10 and $20 \mu \mathrm{M})$ groups.

Cell proliferation assay. A2780/DDP cells were seeded on a 96-well plate (Beyotime Institute of Biotechnology Co., Ltd., Shanghai, China) at a density of $1 \times 10^{4}$ cells/well and incubated with different concentrations of HNPG of $0.625,1.25,2.5,5$, $10,20,40,80$ and $160 \mu \mathrm{M}$ for $24 \mathrm{~h}$ at $37^{\circ} \mathrm{C}$ in a humidified atmosphere containing $5 \% \mathrm{CO}_{2}$, which concentration intervals benefit to screen the most sensitive range of pharmacological activities. Subsequently, $20 \mu 15 \mathrm{mg} / \mathrm{ml}$ MTT stock solution was added to each well, and an additional incubation was performed for $6 \mathrm{~h}$ at $37^{\circ} \mathrm{C}$. A total of $100 \mu \mathrm{l}$ DMSO was added to each well to halt the reaction, and spectrophotometric absorbance was

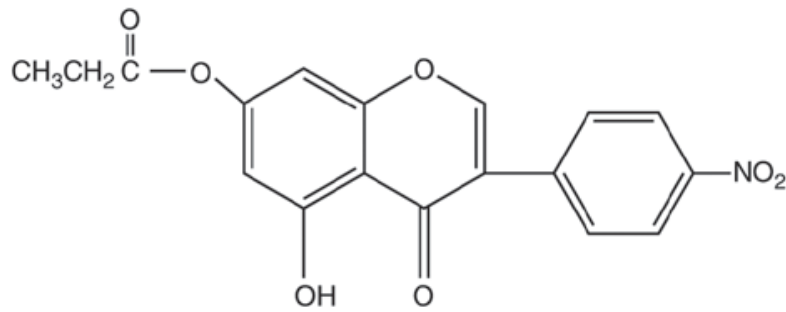

Figure 1. Chemical structure of 5-hydroxy-4'-nitro-7-propionyloxy-genistein.

subsequently measured using a microplate reader (ELX-800; BioTek China, Shanghai, China) at $570 \mathrm{~nm}\left(\mathrm{~A}_{570}\right)$. The proliferative inhibition graph was made based on the rate of proliferation inhibition calculated according to the value of spectrophotometric absorbance. The three most sensitive concentrations of HNPG were selected, then $0.1 \%$ DMSO and different concentrations of HNPG $(5,10$ and $20 \mu \mathrm{M})$ were introduced into each well and sequentially A2780/DDP cells were cultured with complete DMEM medium for 24,48 and $72 \mathrm{~h}$ in humidified $5 \% \mathrm{CO}_{2}$ at $37^{\circ} \mathrm{C}$. The rate of proliferation inhibition (IR) was calculated as follows: (1-average $\mathrm{A}_{570}$ of the experimental group/average $\mathrm{A}_{570}$ of the control group) x100\%. Experiments were performed in triplicate, and the mean value was calculated.

Flat plate clone formation assay. A2780/DDP cells were collected and seeded onto a 6-well plate (Beyotime Institute of Biotechnology Co., Ltd., Shanghai, China) at a density of $3 \times 10^{3}$ cells/well and incubated for $24 \mathrm{~h}$ at $37^{\circ} \mathrm{C}$ in a humidified atmosphere containing $5 \% \mathrm{CO}_{2}$. Then, $0.1 \%$ DMSO or different concentrations of HNPG $(5,10$ or $20 \mu \mathrm{M})$ were added to each well, and the cells were continuously cultured for $48 \mathrm{~h}$. Subsequently, the drug-containing medium was removed, and the cells were washed twice with PBS. Complete DMEM medium was then added, and the cells were cultured for 7 days at $37^{\circ} \mathrm{C}$ in humidified $5 \% \mathrm{CO}_{2}$ until visible clones formed. Clones containing $>50$ cells were defined as one clone, and were fixed with $95 \%$ methanol for $10 \mathrm{~min}$ at room temperature and stained with $0.1 \%$ Giemsa stain for $10 \mathrm{~min}$ at room temperature. Individually-stained clones in each well were counted and the clone formation rate was calculated: The clone formation inhibition rate (\%) was calculated as follows: 1-(the mean number of HNPG group/the mean number of control group) $\mathrm{x} 100 \%$. The results were representative of three independent experiments.

Assessment of the invasive capacity. A pre-cooled 24-well Transwell plate (Beyotime Institute of Biotechnology Co., Ltd., Shanghai, China) was covered with $30 \mu \mathrm{l}$ Matrigel $^{\mathrm{TM}}$ at a $1: 3$ dilution and incubated at $37^{\circ} \mathrm{C}$ for $3 \mathrm{~h}$. Then, A2780/DDP cells $\left(1 \times 10^{5} /\right.$ well) were cultured at $37^{\circ} \mathrm{C}$ for $20 \mathrm{~h}$ in the inner chamber and exposed to $100 \mu 10.1 \%$ FBS/DMEM with $0.1 \%$ DMSO or different doses of HNPG $(5,10$ or $20 \mu \mathrm{M})$, and the outer chamber was filled with $500 \mu 1$ 10\% FBS/DMEM to act as a chemoattractant. Subsequent the membranes of Transwell plate were washed with PBS three times and the invasive cells were fixed with $95 \%$ ethanol for $15 \mathrm{~min}$ at room temperature, and then stained with $0.5 \% \mathrm{H} \& \mathrm{E}$ staining for $15 \mathrm{~min}$ at room temperature. The number of invasive cells 
was manually counted in 5 randomly selected fields under an inverted microscope (N-STORM 4.0; Nikon Corporation, Tokyo, Japan) with magnification, x200. Every group had three repeat wells and the average value was calculated.

Examination of the metastasizing ability. A2780/DDP cells (1x10 $/$ well) were seeded into the inner chamber of 24 -well Transwell plate, treated with $100 \mu 10.1 \%$ FBS/DMEM containing $0.1 \%$ DMSO or different doses of $\operatorname{HNPG}(5,10$ or $20 \mu \mathrm{M}$ ). The inner chamber was placed into the outer chamber containing $500 \mu \mathrm{l} 10 \% \mathrm{FBS} / \mathrm{DMEM}$, and cultured for $16 \mathrm{~h}$ at $37^{\circ} \mathrm{C}$. Following this, the membranes of the Transwell plate were washed with PBS three times, and the metastasized cells were fixed with $4 \%$ paraformaldehyde for $15 \mathrm{~min}$ at room temperature and subsequently stained with $0.1 \%$ crystal violet stain for $15 \mathrm{~min}$ at room temperature. The number of metastasized cells was manually calculated in 5 randomly selected fields under inverted microscope with magnification, x200. Each group had three repeated wells and the mean value was calculated.

Annexin V-fluorescein isothiocyanate (FITC)/propidium iodide (PI) stain apoptosis assay. Groups of A2780/DDP cells were treated with $0.1 \%$ DMSO or different concentrations of HNPG $(5,10$ or $20 \mu \mathrm{M})$ for $48 \mathrm{~h}$, then washed with PBS twice, digested with $0.25 \%$ trypsin, centrifuged $300 \mathrm{x}$ g for $5 \mathrm{~min}$ at room temperature, and the supernatant was discarded. Subsequently, the cells were stained with PI $(50 \mathrm{mg} / \mathrm{ml})$ and Annexin V-FITC $(25 \mathrm{mg} / \mathrm{ml})$ solution (Beyotime Institute of Biotechnology Co., Ltd., Shanghai, China) at room temperature for $15 \mathrm{~min}$ in the dark, and then analyzed within $1 \mathrm{~h}$ using flow cytometry. Excitation and emission wavelengths of 488 and $530 \mathrm{~nm}$, respectively, were selected, and the fraction of the cell populations in different quadrants was analyzed using quadrant statistics. Experiments were performed in triplicate, and the mean value was calculated.

Evaluation of ROS. A2780/DDP cells were treated with $0.1 \%$ DMSO or different concentrations of HNPG $(5,10$ or $20 \mu \mathrm{M}$ ) for $48 \mathrm{~h}$, washed by PBS twice and digested with $0.25 \%$ trypsin, centrifuged $300 \mathrm{x}$ g for $5 \mathrm{~min}$ at room temperature, and the supernatant was discarded. The cells were then

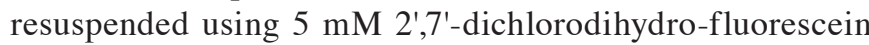
diacetate (DCFH-DA; Bioluminor Biotechnology Co., Ltd., Xiamen, Fujian, China), incubated for $30 \mathrm{~min}$ at $37^{\circ} \mathrm{C}$ in the dark and washed with serum-free DMEM medium three times. Subsequently, the samples were analyzed by flow cytometry using excitation and emission wavelengths of 488 and $530 \mathrm{~nm}$, respectively. The independent experiments were repeated three times, and the average value was calculated.

Measurement of $\Delta \psi m$. A2780/DDP cells were exposed to $0.1 \%$ DMSO or different concentrations of HNPG $(5,10$, $20 \mu \mathrm{M}$ ) for $48 \mathrm{~h}$, washed twice with cold PBS, digested with $0.25 \%$ trypsin, centrifuged $300 \mathrm{x}$ g for $5 \mathrm{~min}$ at room temperature, and the supernatant was discarded, resuspended in $10 \mathrm{mM}$ lipophilic cationic dye 2-(6-Amino-3-imino-3H-xanthen-9-yl) benzoic acid methyl ester (Rh123; Yeasen Biological Technology Co., Ltd., Shanghai, China) for $30 \mathrm{~min}$ at $37^{\circ} \mathrm{C}$ in the dark, and then analyzed by flow cytometry. Excitation and emission wavelengths were 475 and $525 \mathrm{~nm}$, respectively. Experiments were performed in triplicate, and the mean value was calculated.

Western blot analysis. A2780/DDP cells that were treated with $0.1 \%$ DMSO or different concentrations of HNPG $(5,10$ and $20 \mu \mathrm{M}$ ) for $48 \mathrm{~h}$ were washed with cold PBS twice and lysed in 5\% lysis buffer (Beyotime Institute of Biotechnology Co., Ltd., Shanghai, China). The cell lysate was incubated on ice for $15 \mathrm{~min}$ and then centrifuged at $20,000 \mathrm{x} \mathrm{g}$ for $30 \mathrm{~min}$ at $4^{\circ} \mathrm{C}$. The amount of total cell protein was determined by BCA kit (Beyotime Institute of Biotechnology Co.,Ltd., Shanghai, China). Protein aliquots $(50 \mu \mathrm{g})$ were separated by $12 \%$ SDS-PAGE and transferred to nitrocellulose membranes. Non-specific binding sites were blocked by incubating the nitrocellulose membrane for $1 \mathrm{~h}$ at $37^{\circ} \mathrm{C}$ with $5 \%$ non-fat dried milk in TBS containing $0.05 \%$ Tween-20 (TBST). The membranes were incubated for $3 \mathrm{~h}$ at $37^{\circ} \mathrm{C}$ with primary antibodies (rabbit anti-Bcl-2, rabbit anti-Bax, rabbit anti-Cyt-C, rabbit anti-cleaved caspase-9, rabbit anti-cleaved caspase- 3 and rabbit anti-GAPDH antibodies, then washed using TBST buffer three times and 15 minutes every time and incubated with a horseradish peroxidase-conjugated secondary rabbit antibody for $2 \mathrm{~h}$ at $37^{\circ} \mathrm{C}$. The dilutions of all the primary antibodies were 1:1,000, and the dilution of horseradish peroxidase-conjugated secondary rabbit antibody was 1:5,000. Bands were visualized using an enhanced chemiluminescence kit (cat no. AR1170; Boster Biological Technology Co., Ltd., Wuhan, China) and analyzed using Image J (version 1.8.0; National Institutes of Health, Bethesda, MD, USA). Each experiment was repeated three times and the mean value was obtained.

Statistical analysis. SPSS 15.0 software package (SPSS Inc., Chicago, IL, USA) was used for analysis. Data are presented as the mean \pm standard deviation. The means of multiple groups were compared with one-way analysis of variance, after analyzing means using the test for homogeneity of variance, the comparisons among the means were performed using Least-significant Difference, Student-Newman-Keuls and Bonferroni. Multiple post-hoc tests were used in order to demonstrate the statistical significance from multiple-aspect. $\mathrm{P}<0.05$ was considered to indicate a statistically significant difference.

\section{Results}

HNPG inhibits A2780/DDP cell proliferation. A2780/DDP cells were treated with different concentrations of HNPG ranging from $0.625-160 \mu \mathrm{M}$ for $24 \mathrm{~h}$, and the proliferation of A2780/DDP cells was inhibited by HNPG in a dose-dependent manner. The inhibition rate of HNPG concentrations ranging from $0.625-2.5 \mu \mathrm{M}$ or from $40-160 \mu \mathrm{M}$ was non-significant, but the inhibition ratio was markedly increased by concentrations ranging between 2.5-40 $\mu \mathrm{M}$. A2780/DDP cells were exposed to different doses of HNPG $(5,10$ or $20 \mu \mathrm{M})$ for 24 , 48 or $72 \mathrm{~h}$, respectively. The proliferation of A2780/DDP cells was markedly inhibited in a dose-and time-dependent manner; the inhibition rate of every HNPG-treated group was significantly different compared with the control group $\left(\mathrm{P}_{5 \mu \mathrm{M} / 0.1 \%}\right.$ DMSO $\left.<0.05, \mathrm{P}_{10 \mu \mathrm{M} / 0.1 \% \text { DMSO }}<0.05, \mathrm{P}_{20 \mu \mathrm{M} / 0.1 \% \text { DMSO }}<0.05\right)$, and there 

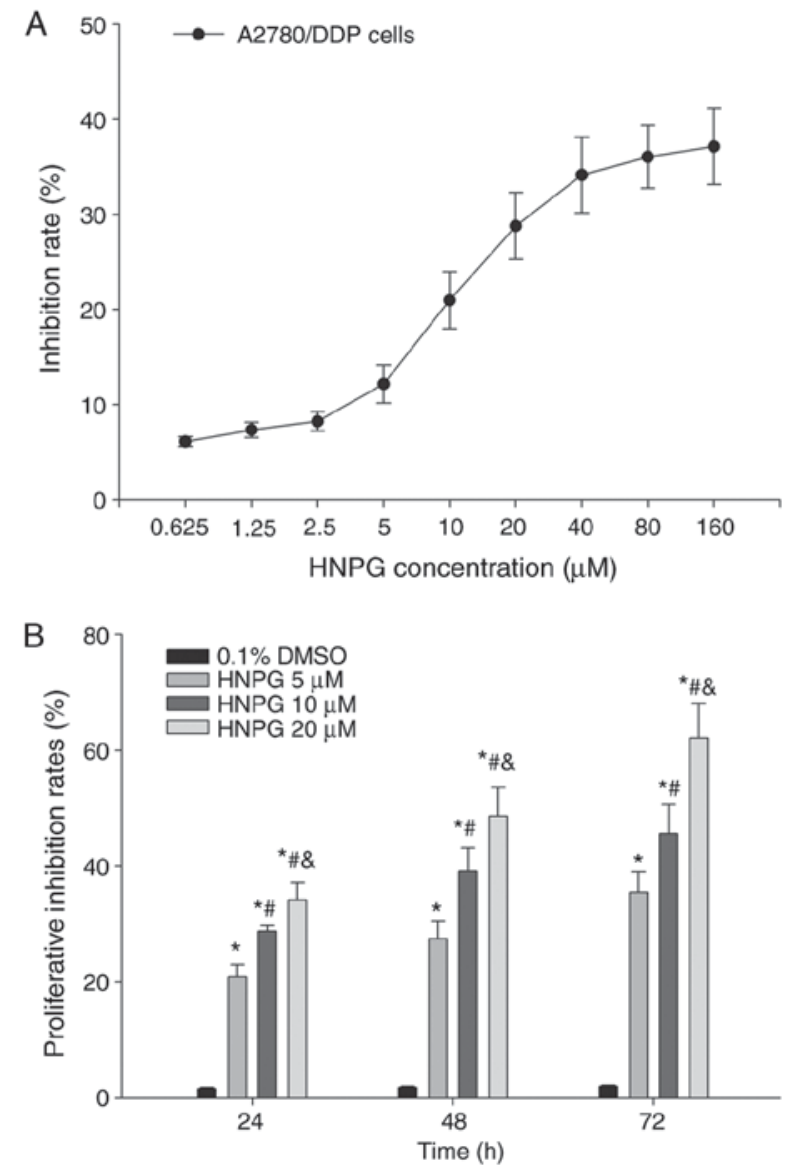

Figure 2. Effects of HNPG on the inhibition of the proliferation rate in A2780/DDP cells. (A) Graph indicating the rate of proliferation inhibition of HNPG ranging from $0.625-160 \mu \mathrm{M}$ for $24 \mathrm{~h}$. (B) The proliferation inhibition rate of different concentrations of HNPG $(5,10$ or $20 \mu \mathrm{M})$ for 24,48 and $72 \mathrm{~h}$. The data are presented as the mean \pm standard deviation from three independent experiments. ${ }^{*} \mathrm{P}<0.05$ vs. $0.1 \%$ DMSO group, ${ }^{~} \mathrm{P}<0.05$ vs. $5 \mu \mathrm{M}$ HNPG group, ${ }^{\circledR} \mathrm{P}<0.05$ vs. $10 \mu \mathrm{M}$ HNPG. HNPG, 5-hydroxy-4'-nitro-7-propionyloxy-genistein; DMSO, dimethyl sulfoxide.

was statistical difference among each HNPG-treated group $\left(\mathrm{P}_{5 / 10 \mu \mathrm{M}}<0.05, \mathrm{P}_{5 / 20 \mu \mathrm{M}}<0.05, \mathrm{P}_{10 / 20 \mu \mathrm{M}}<0.05\right)$. The value of half maximal inhibitory concentrations $\left(\mathrm{IC}_{50}\right)$ were $16.32,12.48$ and $8.64 \mu \mathrm{M}$ for 24,48 and $72 \mathrm{~h}$, respectively, as demonstrated in Fig. 2A and B.

HNPG suppresses A2780/DDP cell clone formation. $\mathrm{A} 2780 / \mathrm{DDP}$ cells were incubated at $37^{\circ} \mathrm{C}$ with $0.1 \%$ DMSO or different concentrations of HNPG $(5,10$ or $20 \mu \mathrm{M})$ for $48 \mathrm{~h}$. Subsequently, the drug-containing medium was removed, and cells were incubated with complete DMEM medium for 7 days until visible clones formed. The rate of clone formation was markedly reduced and the cell number inside the clones was significantly decreased. The inhibition rate of clone formation was significantly increased in a dose-dependent manner; every HNPG-treated group demonstrated a marked statistical difference compared with the control group $\left(\mathrm{P}_{5 \mu \mathrm{M} / 0.1 \% \text { DMso }}<0.05\right.$, $\left.\mathrm{P}_{10 \mu \mathrm{M} / 0.1 \% \text { DMSO }}<0.05, \mathrm{P}_{20 \mu \mathrm{M} / 0.1 \% \text { DMSO }}<0.05\right)$. In addition, there was statistical difference among each HNPG-treated group $\left(\mathrm{P}_{5 / 10 \mu \mathrm{M}}<0.05, \mathrm{P}_{5 / 20 \mu \mathrm{M}}<0.05, \mathrm{P}_{10 / 20 \mu \mathrm{M}}<0.05\right)$. The $\mathrm{IC}_{50}$ of clone formation was $9.36 \mu \mathrm{M}$ for 7 days, as demonstrated in Fig. 3A and $\mathrm{B}$.
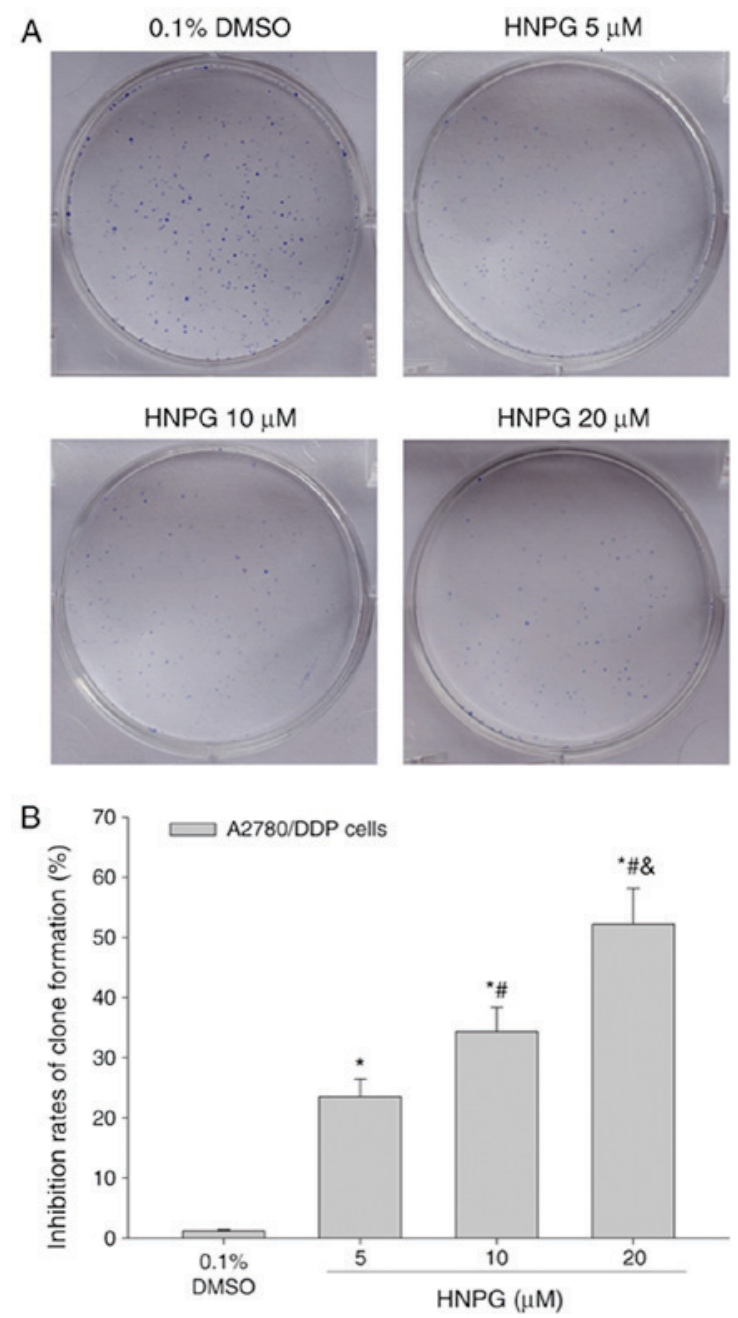

Figure 3. Effects of HNPG on the inhibition rate of clone formation in A2780/DDP cells exposed to different concentrations of HNPG (5, 10 or $20 \mu \mathrm{M}$ ) for 7 days. (A) Images indicating the clone formation of A2780/DDP cells stained with Giemsa stain (magnification, x200). (B) Histogram demonstrating the inhibition rate of clone formation. The data are presented as the mean \pm standard deviation from three independent experiments. ${ }^{~} \mathrm{P}<0.05$ vs. $0.1 \%$ DMSO group, ${ }^{\prime} \mathrm{P}<0.05$ vs. $5 \mu \mathrm{M}$ HNPG group, ${ }^{\&} \mathrm{P}<0.05$ vs. $10 \mu \mathrm{M}$ HNPG. HNPG, 5-hydroxy-4'-nitro-7-propionyloxy-genistein; DMSO, dimethyl sulfoxide.

HNPG inhibits A2780/DDP cell invasion ability. A2780/DDP cells were cultured with $0.1 \%$ DMSO or different concentrations of HNPG $(5,10$ or $20 \mu \mathrm{M})$ for $20 \mathrm{~h}$, and the invasive ability was markedly decreased in a dose-dependent manner. The results demonstrated that the average cell numbers of control, 5, 10 and $20 \mu \mathrm{M}$ groups invading through the Matrigel were $54.25 \pm 4.68,36.75 \pm 3.22,26.64 \pm 2.15$ and $15.76 \pm 1.26$, respectively. There was a statistical difference between each HNPG-treated group and the control $\left(\mathrm{P}_{5 \mu \mathrm{M} / 0.1 \% \text { DMSo }}<0.05\right.$, $\left.\mathrm{P}_{10 \mu \mathrm{M} / 0.1 \% \text { DMso }}<0.05, \mathrm{P}_{20 \mu \mathrm{M} / 0.1 \% \text { DMso }}<0.05\right)$, and there was statistical difference among each HNPG-treated group $\left(\mathrm{P}_{5 / 10 \mu \mathrm{M}}<0.05, \mathrm{P}_{5 / 20 \mu \mathrm{M}}<0.05, \mathrm{P}_{10 / 20 \mu \mathrm{M}}<0.05\right)$, as indicated in Fig. $4 \mathrm{~A}$ and B.

HNPG affects A2780/DDP cells metastasis ability. A2780/DDP cells were cultured with $0.1 \%$ DMSO or different concentrations of HNPG $(5,10$ or $20 \mu \mathrm{M})$ for $16 \mathrm{~h}$, and the metastasizing ability of A2780/DDP cells was significantly 
A

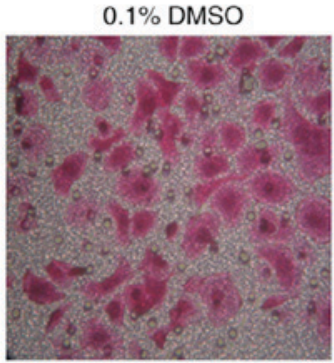

HNPG $10 \mu \mathrm{M}$

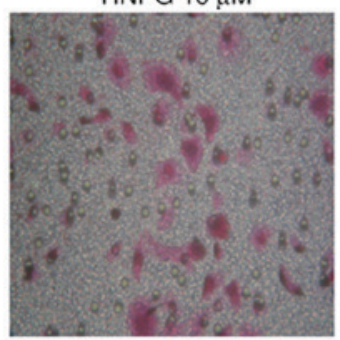

B

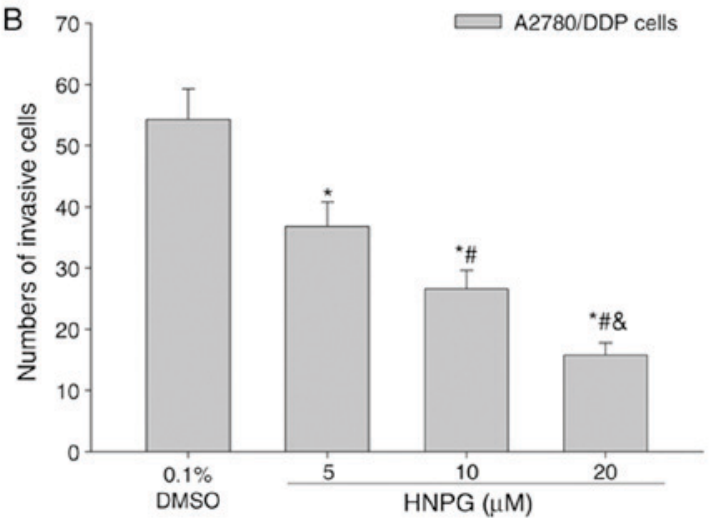

Figure 4. Effects of HNPG on the invasive capabilities of A2780/DDP cells treated with different concentrations of HNPG $(5,10$ or $20 \mu \mathrm{M})$ for $20 \mathrm{~h}$ (A) Images demonstrating A2780/DDP cells in a Matrigel assay and stained with Hematoxylin and Eosin stain (magnification, x200). (B) Histogram exhibiting the number of invasive cells via a Matrigel assay. The data are indicated as the mean \pm standard deviation from three independent experiments. ${ }^{*} \mathrm{P}<0.05$ vs. $0.1 \%$ DMSO group, ${ }^{~} \mathrm{P}<0.05$ vs. $5 \mu \mathrm{M}$ HNPG group, ${ }^{\&} \mathrm{P}<0.05$ vs. $10 \mu \mathrm{M}$ HNPG. HNPG, 5-hydroxy-4'-nitro-7-propionyloxy-genistein; DMSO, dimethyl sulfoxide.

decreased in a concentration-dependent manner. The results demonstrated that the average cell numbers of control, 5, 10 and $20 \mu \mathrm{M}$ groups that metastasized through polycarbonate membrane were $50.36 \pm 4.33,32.45 \pm 3.05,24.12 \pm 2.12$ and $13.86 \pm 1.16$, respectively. There was a statistical difference among every HNPG-treated group $\left(\mathrm{P}_{5 / 10 \mu \mathrm{M}}<0.05, \mathrm{P}_{5 / 20 \mu \mathrm{M}}<0.05\right.$, $\left.\mathrm{P}_{10 / 20 \mu \mathrm{M}}<0.05\right)$, and each HNPG-treated group exhibited a statistical difference compared with the control group $\left(\mathrm{P}_{5 \mu \mathrm{M} / 0.1 \% \mathrm{DMSO}}<0.05, \mathrm{P}_{10 \mu \mathrm{M} / 0.1 \% \mathrm{DMSO}}<0.05, \mathrm{P}_{20 \mu \mathrm{M} / 0.1 \% \mathrm{DMSO}}<0.05\right)$, as demonstrated in Fig. 5A and B.

HNPG induces A2780/DDP cells apoptosis. A2780/DDP cells were exposed to $0.1 \%$ DMSO and different concentrations of HNPG $(5,10$ or $20 \mu \mathrm{M})$ for $48 \mathrm{~h}$, and the apoptotic rate of A2780/DDP cells was significantly enhanced. The results indicated that HNPG may markedly induce A2780/DDP cells apoptosis in a dose-dependent manner; the apoptotic rates of control, 5, 10 and $20 \mu \mathrm{M}$ groups were $0.93 \pm 0.12$,

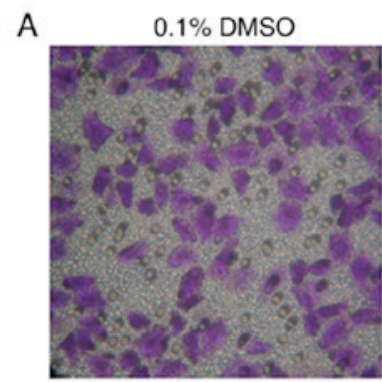

HNPG $10 \mu \mathrm{M}$

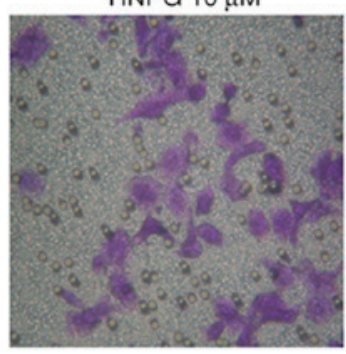

B

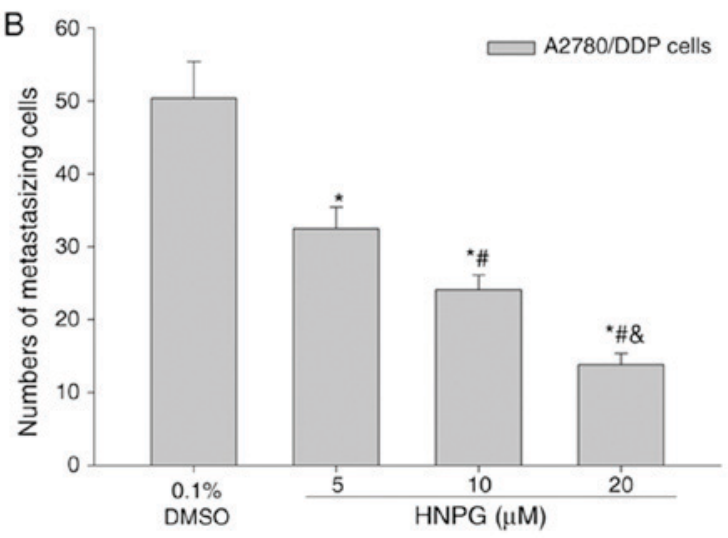

Figure 5. Effects of HNPG on the metastasizing ability of A2780/DDP cells administered with different concentrations of $\operatorname{HNPG}(5,10$ or $20 \mu \mathrm{M})$ for $16 \mathrm{~h}$. (A) Images indicating A2780/DDP cells on a polycarbonate membrane stained with crystal violet stain (magnification, x200). (B) Histogram demonstrating the cell number of metastasis via a polycarbonate membrane. The data are presented as the mean \pm standard deviation from three independent experiments. ${ }^{*} \mathrm{P}<0.05$ vs. $0.1 \%$ DMSO group, ${ }^{~} \mathrm{P}<0.05$ vs. $5 \mu \mathrm{M}$ HNPG group, ${ }^{\&} \mathrm{P}<0.05$ vs. $10 \mu \mathrm{M}$ HNPG group. HNPG, 5-hydroxy-4'-nitro-7-propionyloxy-genistein; DMSO, dimethyl sulfoxide.

$21.09 \pm 2.15,33.69 \pm 3.52$ and $41.39 \pm 4.54 \%$, respectively. Every HNPG-treated group possessed statistical difference compared with control group $\left(\mathrm{P}_{5 \mu \mathrm{M} / 0.1 \% \text { DMSo }}<0.05, \mathrm{P}_{10 \mu \mathrm{M} / 0.1 \%}\right.$ DMSo $\left.<0.05, \mathrm{P}_{20 \mu \mathrm{M} / 0.1 \% \text { DMSO}}<0.05\right)$, and there were significant differences among each HNPG-treated group $\left(\mathrm{P}_{5 / 10 \mu \mathrm{M}}<0.05\right.$, $\left.\mathrm{P}_{5 / 20 \mu \mathrm{M}}<0.05, \mathrm{P}_{10 / 20 \mu \mathrm{M}}<0.05\right)$, as exhibited in Fig. 6A and B.

HNPG affects A2780/DDP cells ROS level. A2780/DDP cells were cultured with $0.1 \%$ DMSO and different concentrations of HNPG $(5,10$ or $20 \mu \mathrm{M})$ for $48 \mathrm{~h}$, the average intensity of fluorescence of DCFH-DA was increased in a dose-dependent manner, which directly represented the level of intracellular ROS. The results exhibited that HNPG may cause oxidative injury in A2780/DDP cells, increase the level of intracellular ROS of A2780/DDP cells; the mean fluorescence intensities of DCFH-DA of control, 5, 10 and $20 \mu \mathrm{M}$ groups were $2.72 \pm 0.25,3.30 \pm 0.29,4.29 \pm 0.40$ and $5.05 \pm 0.51$, respectively. There were statistical differences among each HNPG-treated 
A

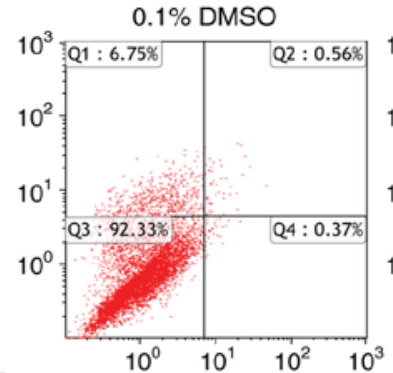

$\overline{0}$
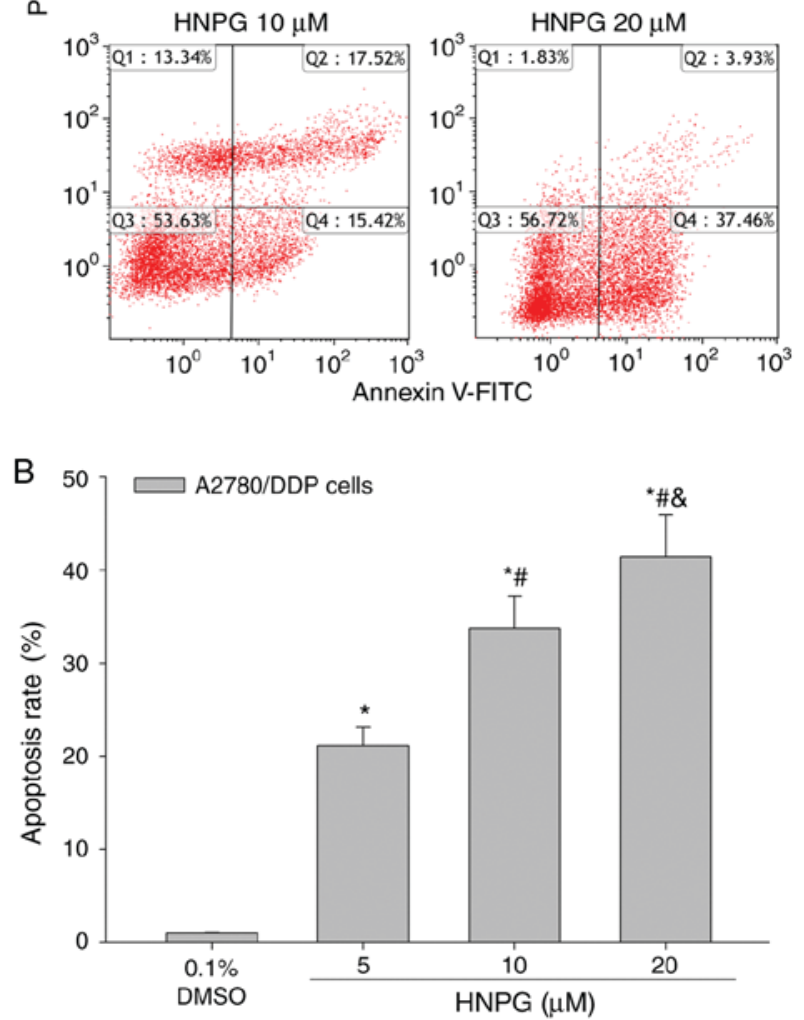

Figure 6. Effects of HNPG on the apoptosis rate of A2780/DDP cells cultured with different concentration of HNPG $(5,10$ or $20 \mu \mathrm{M})$ for $48 \mathrm{~h}$. (A) Diagrams exhibiting the apoptotic percentage A2780/DDP cells stained with Annexin V-FITC/PI. (B) Histogram demonstrating the apoptosis rate. The data are presented as the mean \pm standard deviation from three independent experiments. ${ }^{*} \mathrm{P}<0.05$ vs. $0.1 \%$ DMSO group, ${ }^{\prime} \mathrm{P}<0.05$ vs. $5 \mu \mathrm{M}$ HNPG group, ${ }^{\circledR} \mathrm{P}<0.05$ vs. $10 \mu \mathrm{M}$ HNPG. HNPG, 5-hydroxy-4'-nitro-7-propionyloxy-genistein; DMSO, dimethyl sulfoxide; FITC, fluorescein isothiocyanate; PI, propidium iodide.

group $\left(\mathrm{P}_{5 / 10 \mu \mathrm{M}}<0.05, \mathrm{P}_{5 / 20 \mu \mathrm{M}}<0.05, \mathrm{P}_{10 / 20 \mu \mathrm{M}}<0.05\right)$, and all HNPG-treated groups demonstrated statistical difference compared with the control group $\left(\mathrm{P}_{5 \mu \mathrm{M} / 0.1 \% \mathrm{DMSO}}<0.05, \mathrm{P}_{10 \mu \mathrm{M} / 0.1 \%}\right.$ DMSO $\left.<0.05, \mathrm{P}_{20 \mu \mathrm{M} / 0.1 \% \text { DMSO }}<0.05\right)$, as indicated in Fig. $7 \mathrm{~A}$ and B.

$H N P G$ changes A2780/DDP cell $\Delta \psi m$. A2780/DDP cells were treated to $0.1 \%$ DMSO and different concentrations of HNPG $(5,10$ or $20 \mu \mathrm{M})$ for $48 \mathrm{~h}$, the average intensity of fluorescence of Rh123 was decreased in concentration-dependent manner, which were directly on behalf of the level of $\Delta \psi \mathrm{m}$. The results indicated that HNPG may markedly decrease the $\Delta \psi \mathrm{m}$ of A2780/DDP cells and the mean fluorescence intensities of Rh123 of control, 5, 10 and $20 \mu \mathrm{M}$ groups were $19.4 \pm 2.16,13.7 \pm 1.58,8.38 \pm 0.82$ and $4.61 \pm 0.52$, respectively. There were statistical differences among every HNPG-treated group $\left(\mathrm{P}_{5 \& 10 \mu \mathrm{M}}<0.05, \mathrm{P}_{5 \& 20 \mu \mathrm{M}}<0.05, \mathrm{P}_{10 \& 20 \mu \mathrm{M}}<0.05\right)$, and all
A
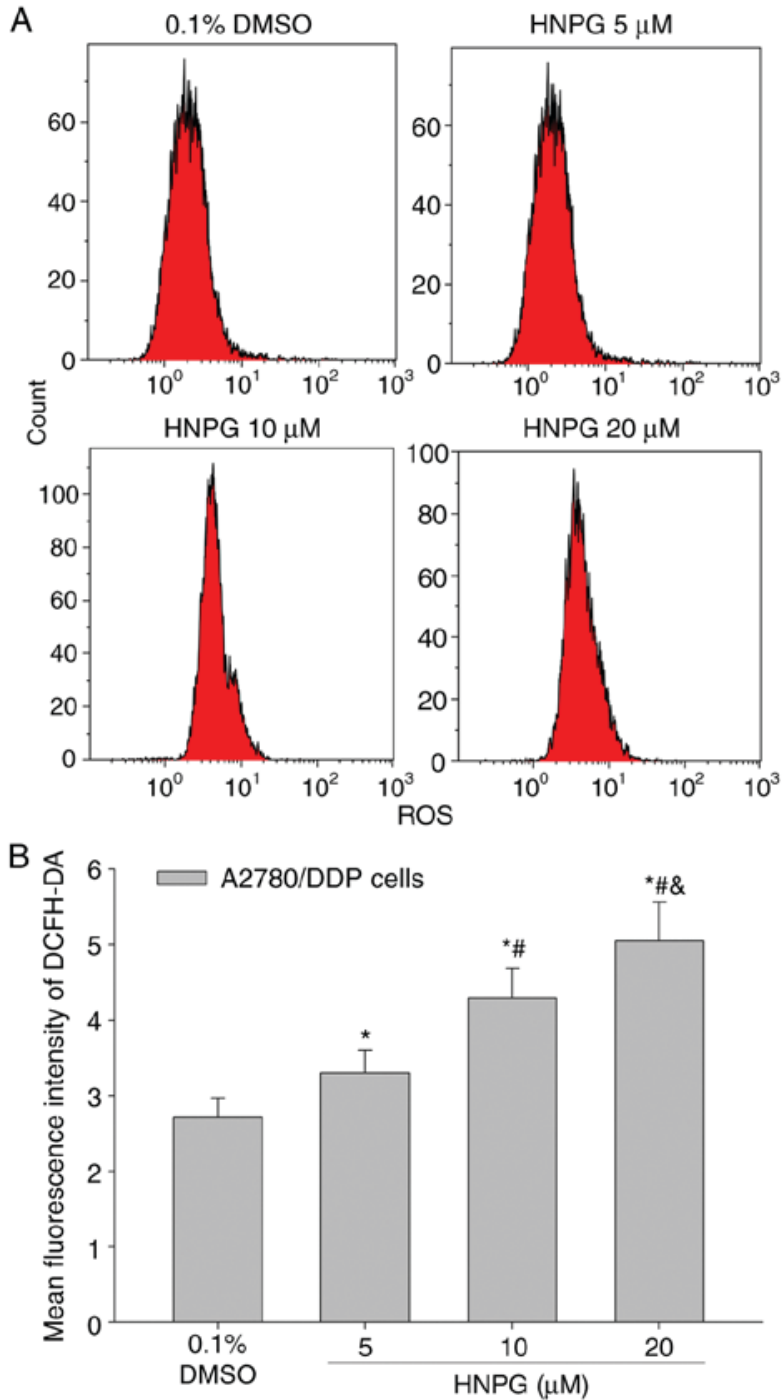

Figure 7. Effects of $\mathrm{HNPG}$ on reactive oxygen species content of A2780/DDP cells incubated with different concentrations of HNPG (5, 10 or $20 \mu \mathrm{M}$ ) for $48 \mathrm{~h}$. (A) Diagrams indicating the average fluorescence intensity of A2780/DDP cells detected using fluorescent probe DCFH-DA. (B) Histogram demonstrating the mean average fluorescence intensity of DCFH-DA. The data are indicated as the mean \pm standard deviation from three independent experiments. ${ }^{*} \mathrm{P}<0.05$ vs. $0.1 \%$ DMSO group, ${ }^{\#} \mathrm{P}<0.05$ vs. $5 \mu \mathrm{M}$ HNPG group, ${ }^{\&} \mathrm{P}<0.05$ vs. $10 \mu \mathrm{M}$ HNPG. HNPG, 5-hydroxy-4'-nitro-7-propionyloxy-genistein; DMSO, dimethyl sulfoxide; DCFH-DA, 2',7'-dichloro-dihydro-fluorescein diacetate.

of HNPG-treated groups demonstrated statistical difference compared with the control group $\left(\mathrm{P}_{5 \mu \mathrm{M} \& 0.1 \% \mathrm{DMSO}}<0.05, \mathrm{P}_{10 \mu \mathrm{M}}\right.$ \& $0.1 \%$ DMSO $\left.<0.05, \mathrm{P}_{20 \mu \mathrm{M} \& 0.1 \% \text { DMSO }}<0.05\right)$, as demonstrated in Fig. 8A and B.

$H N P G$ regulates Bcl-2 family proteins expression, releases Cyt-C from the mitochondria and activates a caspase cascade in A2780/DDP cells. A2780/DDP cells were exposed to $0.1 \%$ DMSO and different concentrations of HNPG $(5,10$ or $20 \mu \mathrm{M}$ ) for $48 \mathrm{~h}$, and the average relative density of Bcl-2, Bax, Cyt-C, cleaved caspase- 9 and cleaved caspase- 3 were analyzed. The Bcl-2 expression level exhibited a decreasing trend, while Bax, Cyt-C, cleaved caspase-9 and cleaved caspase- 3 expression levels increased. The ratio of Bcl-2/Bax also decreased. All HNPG-treated groups exhibited a statistical 
A
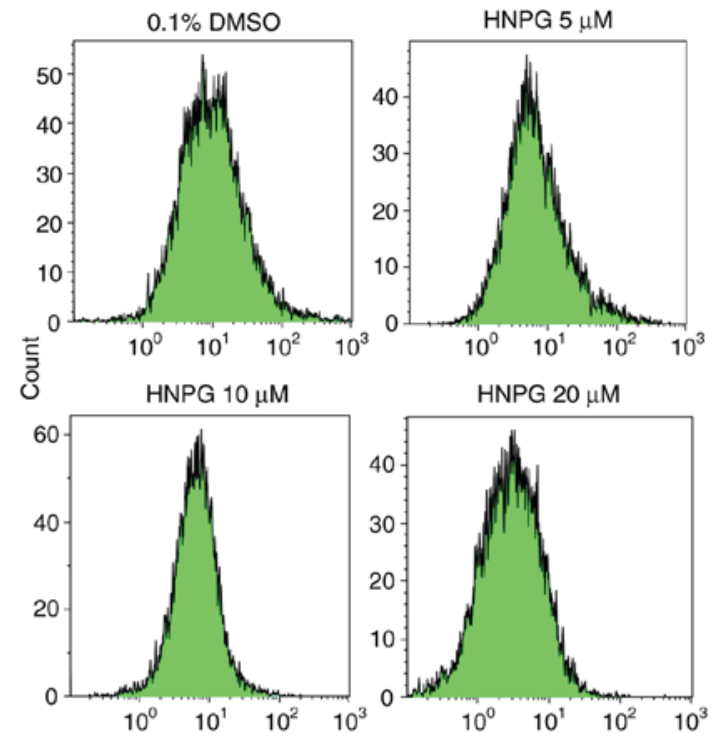

B

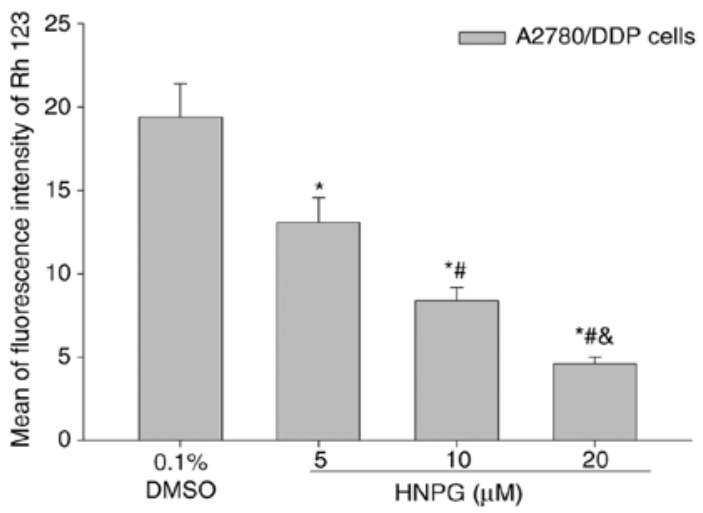

Figure 8. Effects of HNPG on mitochondrial membrane potential of A2780/DDP cells incubated with different concentrations of HNPG (5, 10 or $20 \mu \mathrm{M}$ ) for $48 \mathrm{~h}$. (A) Diagrams demonstrating the average fluorescence density of A2780/DDP cells stained with Rh123. (B) Histogram exhibiting the mean fluorescence density of $\mathrm{Rh} 123$. The data are shown as the mean \pm standard deviation from three independent experiments. ${ }^{*} \mathrm{P}<0.05$ vs. $0.1 \%$ DMSO group, ${ }^{~} \mathrm{P}<0.05$ vs. $5 \mu \mathrm{M}$ HNPG group, ${ }^{\&} \mathrm{P}<0.05$ vs. $10 \mu \mathrm{M}$ HNPG. Rh123, 2-(6-Amino-3- imino-3H-xanthen-9-yl) benzoic acid methyl ester; HNPG, 5-hydroxy-4'-nitro-7-propionyloxy-genistein; DMSO, dimethyl sulfoxide.

difference compared with the control group $\left(\mathrm{P}_{5 \mu \mathrm{M} / 0.1 \% \text { DMSO }}\right.$ $\left.<0.05, \mathrm{P}_{10 \mu \mathrm{M} / 0.1 \% \text { DMso }}<0.05, \mathrm{P}_{20 \mu \mathrm{M} / 0.1 \% \text { DMso }}<0.05\right)$ in Bcl-2, Bax, Cyt-C, cleaved caspase-9, cleaved caspase-3 expression levels and the ratio of $\mathrm{Bcl}-2 / \mathrm{Bax}$. There were statistical differences among every HNPG-treated group in Bax, Cyt-C, cleaved caspase-9, cleaved caspase-3 expression levels and the ratio of Bcl-2/Bax $\left(\mathrm{P}_{5 / 10 \mu \mathrm{M}}<0.05, \mathrm{P}_{5 / 20 \mu \mathrm{M}}<0.05, \mathrm{P}_{10 / 20 \mu \mathrm{M}}<0.05\right)$. There were significant differences between the $5 \mu \mathrm{M}$ HNPG-treated group and the 10 or $20 \mu \mathrm{M}$ HNPG-treated groups in $\mathrm{Bcl}-2$ expression $\left(\mathrm{P}_{5 / 10 \mu \mathrm{M}}<0.05\right.$ or $\left.\mathrm{P}_{5 / 20 \mu \mathrm{M}}<0.05\right)$, but there were no difference between the 10 and $20 \mu \mathrm{M}$ HNPG-treated groups in Bcl-2 expression ( $\left.\mathrm{P}_{10 / 20 \mu \mathrm{M}}>0.05\right)$, as exhibited in Fig. 9A-D.

\section{Discussion}

Proliferation, invasion and metastasis are basic characteristics of tumors and these features have also become the normal indices of measuring pharmacological activity $(13,14)$. The speed of proliferation and clone formation, and the capacities for invasion and metastasis directly reflect the malignant degree of tumors. Malignant tumors not only germinate in the primary site via infiltrating and damaging adjacent organs and tissues, but also metastasize to other areas to proliferate and grow $(15,16)$. Therefore, the fundamental methods of evaluating the pharmacological effects of chemotherapeutics are detecting their ability to inhibit the proliferation, clone formation, invasion and metastasis of cancer cells. previous studies have suggested that HNPG demonstrated inhibition of proliferation in gastric and breast cancer cells in vitro $(11,12)$, but its molecular mechanism of this inhibition of proliferation has not yet been elucidated. In the present study, the data demonstrated that HNPG suppressed proliferation, clone formation, invasion and metastasis, and induced apoptosis of human ovarian cancer A2780/DDP cells in a concentration-and time-dependent manner, which demonstrated novel antitumor effects of HNPG compared with previous studies $(11,12)$. These experimental results suggested HNPG may be an excellent novel candidate for therapy in human ovarian cancer A2780/DDP cells.

Apoptosis is a type of programmed cell death that occurs in small areas or small numbers of cells at a time, and serves an important role in the genesis and development of embryos, alternation of new and old mature cells, biological degradation, inflammation, atrophy, aging, autoimmune diseases and tumors (17). In the early phase of apoptosis, cell membrane phospholipids are asymmetrically lost, which results in phosphatidylserine exposure at the cell surface. These exposed phosphatidylserine molecules at the cell surface exhibit a strong binding ability with Annexin $\mathrm{V}$ in the presence of calcium (18). During the late phase of apoptosis, propidium iodide (PI) enters the cytoplasm through the cell membrane, and combines with the nucleus (19). In the results of the present study, the numbers of Annexin V/PI-positive A2780/DDP cells were markedly enhanced, in a dose-dependent manner, following HNPG treatment for $48 \mathrm{~h}$. Therefore, it was suggested that the HNPG-mediated inhibition of proliferation, clone formation, invasion and metastasis of A2780/DDP cells may occur via an apoptotic pathway.

ROS include a series of molecules that directly or indirectly originate from oxygen molecules and possess more biological activities than oxygen molecules in cells that are regarded as signaling molecules that regulate cell proliferation, differentiation, survival and immune responses (19). Numerous in vitro studies have revealed that the death of cancer cells was accompanied by a marked accumulation of intracellular ROS, significant increases in metabolic activity and markedly damaged mitochondrial function (20). The damage to mitochondria may promote the creation of ROS in cells, while the generation of intracellular ROS may conversely cause a lipid peroxidation reaction, which lead to various cellular events inducing cell apoptosis or necrosis (21). In the present study, the content of ROS in human ovarian cancer A2780/DDP cells was markedly increased following HNPG treatment for $48 \mathrm{~h}$. Therefore, it was suggested that the HNPG-mediated inhibition of proliferation, clone formation, invasion, metastasis and induction of apoptosis may be through ROS accumulation in A2780/DDP cells.

It is well-known that mitochondria serve a crucial function in the extrinsic and intrinsic pathways of apoptosis; the structural integrity and normal function of mitochondrial 
A

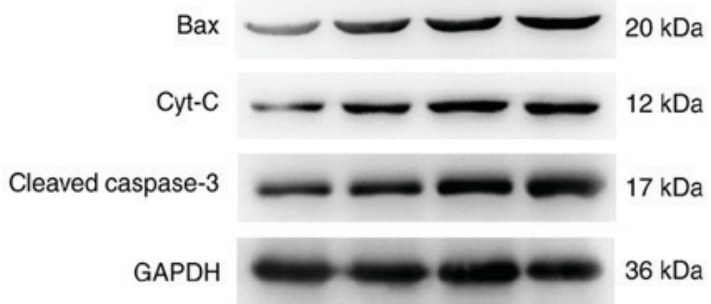

C

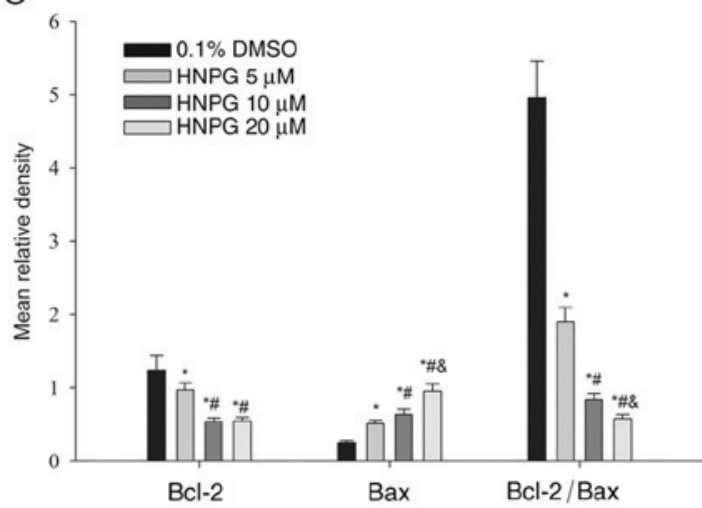

B

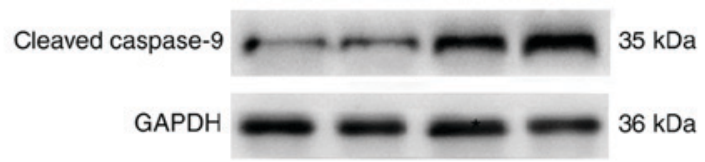

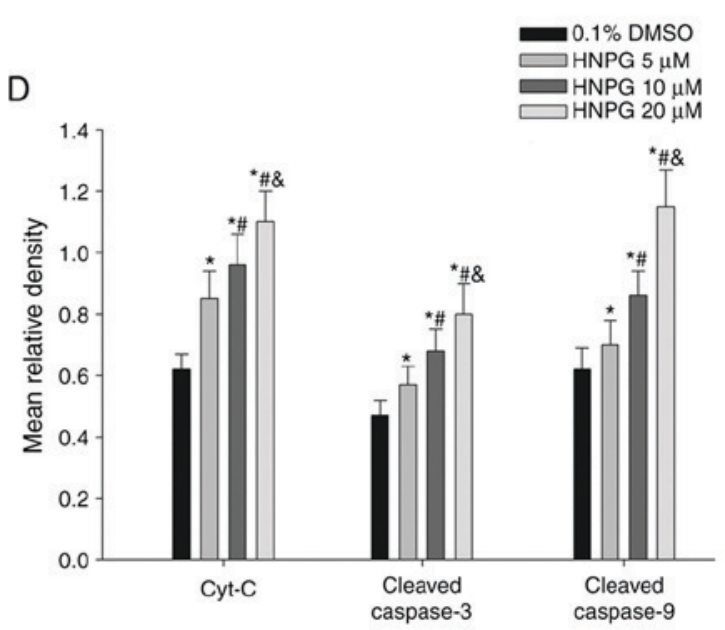

Figure 9. The protein expression changes of A2780/DDP cells incubated with different concentrations of HNPG $(5,10$ or $20 \mu \mathrm{M})$ for $48 \mathrm{~h}$ (A and B) Electrophoretograms demonstrating the expression of Bcl-2, Bax, Cyt-C, cleaved caspase-3, cleaved caspase-9. (C) Histogram demonstrating the mean relative gray density value of Bcl-2, Bax, and the ratio of Bcl-2/Bax. (D) Histogram indicating the average relative gray density value of Cyt-C, cleaved caspase- 3 and cleaved caspase-9. The data are represented as the mean \pm standard deviation for three independent experiments. ${ }^{*} \mathrm{P}<0.05$ vs. $0.1 \%$ DMSO group, ${ }^{\sharp} \mathrm{P}<0.05$ vs. $5 \mu \mathrm{M}$ HNPG group, ${ }^{\&} \mathrm{P}<0.05$ vs. $10 \mu \mathrm{M}$ HNPG. HNPG, 5-hydroxy-4'-nitro-7-propionyloxy- genistein; DMSO, dimethyl sulfoxide; Bcl-2, B-cell lymphoma 2; Bax, Bcl-2 associated X protein; Cyt-C, cytochrome C.

membranes are critical for cell survival (22). Notably, if the structure and function of mitochondrial membranes sustain damage, for example through ultraviolet irradiation, genotoxic agents or oxidative stress, this will trigger a series of cellular events that will affect the basic characteristics of malignant tumors, such as the proliferation, invasion and metastasis, and even induce cells apoptosis or necrosis (23). Bcl-2 and Bax are the most important apoptosis-inducing factors that function in the mitochondrial membrane, jointly constituting certain ion channels that regulate mitochondrial permeability transition (MPT). Once the mitochondrial membrane is subjected to damage, Bcl-2, Bax and the ratio of Bcl-2/Bax will be altered, which will trigger a series of cellular events releasing Cyt-C from mitochondria (24). In the present study, in A2780/DDP cells incubated with different concentrations of HNPG, it was demonstrated that the ROS content was notably increased, along with marked decreases in $\Delta \psi \mathrm{m}$, a downregulation of $\mathrm{Bcl}-2$, upregulation of $\mathrm{Bax}$ and decreases in the $\mathrm{Bcl}-2 / \mathrm{Bax}$ ratio. These results suggest that HNPG-mediated apoptosis may occur through the mitochondrial pathway.

The caspase family serves a central role in regulating apoptosis (25). It has been established that caspase- 8 or caspase-9 is activated by apoptosis stimulating factors, for example Cyt-C or the Fas Ligand-Fas-Fas-associated protein with death domain complex, which will trigger the downstream caspase-3, and the activated caspase- 3 will directly cause the loss of DNA repair function and activation of endonuclease and DNA fragmentation, resulting in cell apoptosis $(26,27)$. In the present study, it was observed that the A2780/DDP cells exposed to different concentrations of HNPG underwent apoptosis in a dose-dependent manner, accompanied by the upregulation of Cyt-C, cleaved caspase- 9 and cleaved caspase-3. The observed caspase-mediated properties of HNPG were in agreement with the basic properties and functions of the caspase family (27). Therefore, these results suggested that HNPG-triggered apoptosis was potentially mediated, at least in part, by this caspase cascade.

In conclusion, HNPG demonstrated significant cytotoxic activity in human ovarian cancer A2780/DDP cells. HNPG inhibited the rates of proliferation, clone formation, invasion and metastasis, and induced apoptosis in vitro. Simultaneously, the levels of intracellular ROS and $\Delta \psi \mathrm{m}$ were increased and decreased, respectively. Additionally, HNPG downregulated the expression of $\mathrm{Bcl}-2$, upregulated the expression of $\mathrm{Bax}$, led to $\mathrm{Cyt}-\mathrm{C}$ release from mitochondria, activated caspase- 9 and caspase- 3 and caused cell apoptosis. Compared with previous studies examining HNPG $(11,12)$, the present study not only detected its anti-proliferative effects, but also examined the inhibitory effects on clone formation, invasion and metastasis, induction of apoptosis, accumulation of ROS and alteration of $\Delta \psi \mathrm{m}$. The present study demonstrated the antitumor effect of HNPG from multiple perspectives and additionally investigated the basic molecular biological mechanism of HNPG. The results not only provided additional data concerning the antitumor effects of HNPG, but also aimed to elucidate the 
basic molecular biological mechanisms involved. In summary, HNPG indicated a marked cytotoxic activity in human ovarian cancer A2780/DDP cells via the ROS-mediated mitochondrial dysfunction pathway, which suggests that HNPG may be a novel candidate for chemotherapeutic drug development. Although the antitumor effect of HNPG and its basic molecular biological mechanism were detected in vitro, there are several limitations requiring additional investigation, such as the absence of data of the antitumor mechanism on A2780 cells which may assist to elucidate the underlying resistance mechanisms of HNPG on A2780 cells, the lack of data on normal cells that may explain the side effects of HNPG on normal cells and tissues and organs, the absence of data on positive control groups, for example 5-fluoracil, paclitaxel and methotrexate, which may assist in illuminating the pharmacological effects of HNPG and the effective pharmacological ratio between HNPG and clinical common drugs. Subsequent studies will investigate the metabolism of HNPG in experimental animal models, detect its blood drug concentration and its half-life and the side effects on the brain, heart, lung, liver and kidney cells.

\section{Acknowledgements}

The present study was supported by The First Clinical School of Jinan University (grant no. FRPR201601-04). The authors would like to thank Professor Wanyu Xie (the First Affiliated Hospital of University of South China, Hengyang, Hunan, China) for her technical assistance.

\section{Competing interests}

The authors declare that they have no competing interests.

\section{References}

1. Wijdeven RH, Pang B, Assaraf YG and Neefjes J: Old drugs, novel ways out: Drug resistance toward cytotoxic chemotherapeutics. Drug Resist Updat 28: 65-81, 2016.

2. Bergamini A, Pisano C, Di Napoli M, Arenare L, Della Pepa C, Tambaro R, Facchini G, Gargiulo P, Rossetti S, Mangili G, et al: Cisplatin can be safely administered to ovarian cancer patients with hypersensitivity to carboplatin. Gynecol Oncol 144: 72-76, 2017.

3. Brozovic A: The relationship between platinum drug resistance and epithelial-mesenchymal transition. Arch Toxicol 91: 605-619, 2017.

4. Jin L, Xu M, Luo XH and Zhu XF: Stephania tetrandra and ginseng-containing Chinese herbal formulation NSENL reverses cisplatin resistance in lung cancer xenografts. Am J Chin Med 45: 385-401, 2017.

5. Henklewska M, Pawlak A, Pruchnik H and Obminska-Mrukowicz B: Complex of platinum(II) with tris(2-carboxyethyl) phosphine induces apoptosis in canine lymphoma/leukemia cell lines. Anticancer Res 37: 539-546, 2017.

6. Chen Y, Cass SL, Kutty SK, Yee EM, Chan DS, Gardner CR, Vittorio O, Pasquier E, Black DS and Kumar N: Synthesis, biological evaluation and structure-activity relationship studies of isoflavene based mannich bases with potent anti-cancer activity. Bioorg Med Chem Lett 25: 5377-5383, 2015.

7. Uesawa Y, Sakagami H, Kagaya H, Yamashita M, Takao K and Sugita Y: Quantitative structure-cytotoxicity relationship of 3-benzylidenechromanones. Anticancer Res 36: 5803-5812, 2016.

8. Wootten D, Simms J, Koole C, Woodman OL, Summers RJ, Christopoulos A and Sexton PM: Modulation of the glucagon-like peptide-1 receptor signaling by naturally occurring and synthetic flavonoids. J Pharmacol Exp Ther 336: 540-550, 2011.
9. Nagib DA and MacMillan DW: Trifluoromethylation of arenes and heteroarenes by means of photoredox catalysis. Nature 480: 224-228, 2011.

10. Lv H, Yang J, Wang C, Yu F, Huang D and Ye L: The WNT7B protein promotes the migration and differentiation of human dental pulp cells partly through WNT/beta-catenin and c-Jun N-terminal kinase signalling pathways. Arch Oral Biol 87: 54-61, 2017.

11. Wang JH, Gao CJ and Meng Lk: Study on the synthesis and antitumor effects of 5-Hydroxy-4'-nitro-7-propionyloxy-isoflavone. China Pharmacist 15: 1378-1385, 2012 (In Chinese).

12. Jin YS, Liu CM, Wu QY, Yao B, Dai Y, Zhang LR and Shen XL: Design and synthesis of genistein derivatives 5-hydroxy-4'-nitro-7-substituted acyloxy isoflavone and their antitumor effects. Acad J Mil Med Univ 26: 182-185, 2005 (In Chinese).

13. Singh S, Guetzko M and Resnick K: Preoperative predictors of delay in initiation of adjuvant chemotherapy in patients undergoing primary debulking surgery for ovarian cancer. Gynecol Oncol 143: 241-245, 2016.

14. Xu Z, Mei J and Tan Y: Baicalin attenuates DDP (cisplatin) resistance in lung cancer by downregulating MARK 2 and p-Akt. Int J Oncol 50: 93-100, 2017

15. Solmaz Hasdemir P and Guvena T: Borderline ovarian tumors A contemporary review of clinicopathological characteristics, diagnostic methods and therapeutic options. J Buon 21: 780-786, 2016.

16. Erdogan S, Turkekul K, Serttas R and Erdogan Z: The natural flavonoid apigenin sensitizes human CD44+ prostate cancer stem cells to cisplatin therapy. Biomed Pharmacother 88: 210-217, 2017.

17. Mirzaei MR, Mahmoodi M, Hassanshahi G and Ahmadi Z: Down-regulation of anti-apoptotic genes in tumor cell lines is facilitated by suppression of OCT4B1. Adv Med Sci 62: 97-102, 2016.

18. Jian KL,Zhang C, Shang ZC, Yang Land Kong LY: Eucalrobusone $\mathrm{C}$ suppresses cell proliferation and induces ROS-dependent mitochondrial apoptosis via the p38 MAPK pathway in hepatocellular carcinoma cells. Phytomedicine 25: 71-82, 2017.

19. Han X, Zhen S, Ye Z, Lu J, Wang L, Li P, Li J, Zheng X, Li H Chen W, et al: A feedback loop between miR-30a/c-5p and DNMT1 mediates cisplatin resistance in ovarian cancer cells. Cell Physiol Biochem 41: 973-986, 2017.

20. Bauer G: Central signaling elements of intercellular reactive oxygen/nitrogen species-dependent induction of apoptosis in malignant cells. Anticancer Res 37: 499-513, 2017.

21. Pluchino LA, Choudhary S and Wang HC: Reactive oxygen species-mediated synergistic and preferential induction of cell death and reduction of clonogenic resistance in breast cancer cells by combined cisplatin and FK228. Cancer Lett 381: 124-132, 2016.

22. Bauer D, Werth F, Nguyen HA, Kiecker F and Eberle J: Critical role of reactive oxygen species (ROS) for synergistic enhancement of apoptosis by vemurafenib and the potassium channel inhibitor TRAM-34 in melanoma cells. Cell Death Dis 8: e2594, 2017.

23. Zajac J, Kostrhunova H, Novohradsky V, Vrana O, Raveendran R, Gibson D, Kasparkova J and Brabec V: Potentiation of mitochondrial dysfunction in tumor cells by conjugates of metabolic modulator dichloroacetate with a Pt (IV) derivative of oxaliplatin. J Inorg Biochem 156: 89-97, 2016.

24. Vijayarathna S, Oon CE, Chen Y, Kanwar JR and Sasidharan S: Polyalthia longifolia methanolic leaf extracts (PLME) induce apoptosis, cell cycle arrest and mitochondrial potential depolarization by possibly modulating the redox status in hela cells. Biomed Pharmacother 89: 499-514, 2017.

25. Nasser MI, Masood M, Wei W, Li X, Zhou Y, Liu B, Li J and Li X: Cordycepin induces apoptosis in SGC-7901 cells through mitochondrial extrinsic phosphorylation of PI3K/Akt by generating ROS. Int J Oncol 50: 911-919, 2017.

26. Hsin IL, Wang SC, Li JR, Ciou TC, Wu CH, Wu HM and Ko JL: Immunomodulatory proteins FIP-gts and chloroquine induce caspase-independent cell death via autophagy for resensitizing cisplatin-resistant urothelial cancer cells. Phytomedicine 23: 1566-1573, 2016.

27. Leekha A, Gurjar BS, Tyagi A, Rizvi MA and Verma AK: Vitamin $C$ in synergism with cisplatin induces cell death in cervical cancer cells through altered redox cycling and p53 upregulation. J Cancer Res Clin Oncol 142: 2503-2514, 2016. 